\title{
Synthesis and X-ray Diffraction Study of thiosemicarbazone Palladacycles with dppm ${ }^{\dagger}$
}

\author{
Marcos Rúa-Sueiro *, Paula Munin-Cruz, Francisco Reigosa, José M. Vila and Juan M. Ortigueira \\ 1 Department of Inorganic Chemistry, Faculty of Chemistry, University of Santiago de Compostela, \\ Avda. das Ciencias s/n, 15782 Santiago de Compostela, Spain; paula.munin@usc.es (P.M.-C.); \\ francisco.reigosa@usc.es (F.R.); josemanuel.vila@usc.es (J.M.V.); juanm.ortigueira@usc.es (J.M.O.) \\ * Correspondence: marcos.rua.sueiro@usc.es \\ + Presented at the 2nd International Electronic Conference on Crystals, 10-20 November 2020; Available \\ online: https://iocc_2020.sciforum.net/.
}

Published: 22 January 2021

\begin{abstract}
Cyclometallated compounds have been extensively studied, in particular those with palladium and platinum. This is because of their possible applications in medicinal chemistry, as anticancer or antimicrobial agents; in some cases, with similar results as cisplatin, carboplatin or oxaliplatin. What is also remarkable is their use as homogeneous catalysts, for example, in cross coupling reactions such as Suzuki-Miyaura or Mizoroki-Heck. Herein, we report the synthesis of different thiosemicarbazone ligands, which will be reacted with a palladium or platinum salt, to give the corresponding cyclometallated compounds; in addition, their reactivity with bis(diphenylphosphino)methane (dppm) will be studied. Characterization has been carried out by elemental analysis, IR spectroscopy, ${ }^{1} \mathrm{H}$ and ${ }^{31} \mathrm{P}$ NMR spectroscopy. Additionally, $1 \mathrm{c}$ has been studied by X-ray diffraction.
\end{abstract}

Keywords: cyclometallation; thiosemicarbazone; palladium; platinum; X-ray diffraction

\section{Introduction}

Palladium and platinum cyclometallated compounds have been studied due to their interesting applications in several chemical fields.

On the one hand, they are useful in synthetic organic chemistry, as catalysts in many reactions with formation of $\mathrm{C}-\mathrm{C}$ and $\mathrm{C}-\mathrm{N}$ bonds [1-6].

On the other hand, their cytotoxic activity has been considered in biological assays [7-11], showing in some cases significant results in this field.

There are many characterization techniques that could be used for this kind of complex. Probably the most precise one is single crystal X-Ray diffraction, which in this research work is given for compound 1c.

\section{Experimental}

\subsection{Ligands}

The ligands were synthesized according to Scheme 1. First, the thiosemicarbazide and hydrochloric acid $\left(0.4 \mathrm{~cm}^{3}\right)$ were added in water $\left(20 \mathrm{~cm}^{3}\right)$. After complete solubilization, the corresponding amount of ketone (shown in Table 1) was added. The mixture was stirred at room temperature for $8 \mathrm{~h}$, after which a white solid appeared, that was filtered, washed with water and dried under vacuum. 
<smiles>COc1ccc(C(C)=O)cc1</smiles><smiles>[R]NC(=S)NN</smiles><smiles>[OH2+][OH2+]</smiles>

$\mathrm{R}=\mathrm{H}, \mathrm{Me}, \mathrm{Et}$<smiles>[R]NC(=S)N/N=C(\C)c1ccc(OC)cc1</smiles>

1a-3a

Scheme 1. Synthesis of thiosemicarbazone ligands.

Table 1. Quantities of reagents added.

\begin{tabular}{ccccc}
\hline Ligand & $\mathbf{R}$ & Thiosemicarbazide $\mathbf{( m g )}$ & Ketone $\mathbf{( m g )}$ & Yield (\%) \\
\hline 1a & $\mathrm{H}$ & 250 & 412 & 90 \\
2a & $\mathrm{Me}$ & 250 & 357 & 98 \\
3a & $\mathrm{Et}$ & 250 & 315 & 88 \\
\hline
\end{tabular}

\subsection{Cyclometallated Compounds}

Cyclometallation was carried out following Scheme $2 . \mathrm{K}_{2} \mathrm{MCl}_{4}(\mathrm{M}=\mathrm{Pd}, \mathrm{Pt})$ was added in $6 \mathrm{~cm}^{3}$ of water. After total solubilization, the corresponding amount of each thiosemicarbazone ligand (shown in Table 2) was added in ethanol $\left(25 \mathrm{~cm}^{3}\right)$. The mixture was stirred at room temperature for $24 \mathrm{~h}$. A suspension formed, that was centrifugated and the solid was dried under vacuum.<smiles>[R]NC(=S)N/N=C(\C)c1ccc(OC)cc1</smiles>

$\mathrm{R}=\mathrm{H}, \mathrm{Me}, \mathrm{Et}$

1a-3a

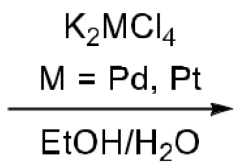

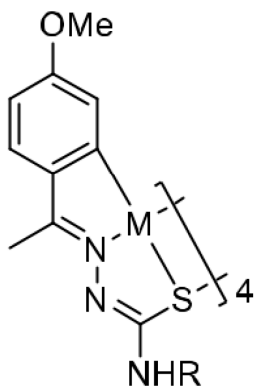

$M=P d \mathbf{1 b}-\mathbf{3 b}$

$M=P t \mathbf{4 b}-6 b$

Scheme 2. Synthesis of cyclometallated compounds.

Table 2. Quantities of reagents added.

\begin{tabular}{cccccc}
\hline Compound & $\mathbf{R}$ & $\mathbf{M}$ & K2MCl4 $\mathbf{( m g )}$ & Thiosemicarbazone $\mathbf{( m g )}$ & Yield (\%) \\
\hline $\mathbf{1 b}$ & $\mathrm{H}$ & $\mathrm{Pd}$ & 200 & 164 & 71 \\
$\mathbf{2 b}$ & $\mathrm{Me}$ & $\mathrm{Pd}$ & 200 & 174 & 78 \\
$\mathbf{3 b}$ & $\mathrm{Et}$ & $\mathrm{Pd}$ & 200 & 185 & 86 \\
$\mathbf{4 b}$ & $\mathrm{H}$ & $\mathrm{Pt}$ & 150 & 80.7 & 85 \\
$\mathbf{5 b}$ & $\mathrm{Me}$ & $\mathrm{Pt}$ & 150 & 85.8 & 85 \\
$\mathbf{6 b}$ & $\mathrm{Et}$ & $\mathrm{Pt}$ & 150 & 90.8 & 86 \\
\hline
\end{tabular}

\subsection{Reactivity with dppm}

Compounds 1c-6c were synthesized following Scheme 3. The cyclometallated compoundsand the corresponding amount of bis(diphenylphosphino)methane (dppm) (shown in Table 3) were 
added under nitrogen in $15 \mathrm{~cm}^{3}$ of oxygen-free acetone. After stirring at $50{ }^{\circ} \mathrm{C}$ for $24 \mathrm{~h}$, a solid was obtained, that was centrifugated and dried under vacuum.

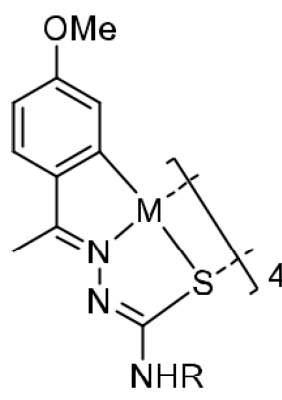

$M=P d \mathbf{1 b}-\mathbf{3 b}$

$M=P t \mathbf{4 b - 6 b}$

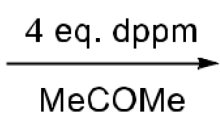<smiles>[R]Nc1nn(P(CPc2ccccc2)c2ccccc2)c(C)c2c3ccc(OC)cc3n1-2</smiles>

$M=P d 1 c-3 c$

$M=P t 4 c-6 c$

Scheme 3. Reactions with dppm.

Table 3. Quantities of reagents added.

\begin{tabular}{cccccc}
\hline Compound & $\mathbf{R}$ & $\mathbf{M}$ & Metallacycle $\mathbf{( m g )}$ & dppm $\mathbf{( m g})$ & Yield (\%) \\
\hline 1c & $\mathrm{H}$ & $\mathrm{Pd}$ & 35 & 41.0 & 60 \\
2c & $\mathrm{Me}$ & $\mathrm{Pd}$ & 35 & 39.3 & 75 \\
3c & $\mathrm{Et}$ & $\mathrm{Pd}$ & 35 & 37.8 & 72 \\
4c & $\mathrm{H}$ & $\mathrm{Pt}$ & 35 & 32.3 & 64 \\
5c & $\mathrm{Me}$ & $\mathrm{Pt}$ & 35 & 31.3 & 59 \\
6c & $\mathrm{Et}$ & $\mathrm{Pt}$ & 35 & 30.2 & 61 \\
\hline
\end{tabular}

\section{Results and Discussion}

All the compounds were characterized by IR spectroscopy, ${ }^{1} \mathrm{H}$ and ${ }^{31} \mathrm{P}$ NMR spectroscopy. In addition, compound $1 \mathrm{c}$ was characterized by single crystal X-ray diffraction.

\subsection{IR Spectroscopy}

IR spectroscopy characterization data for the thiosemicarbazone ligands and cyclometallated compounds are shown in Table 4 . The deprotonation and the loss of the $\mathrm{C}=\mathrm{S}$ double bond character are required for cyclometallation to occur.

Table 4. IR spectroscopy characterization.

\begin{tabular}{ccccc}
\hline Compound & $\mathbf{R}$ & $\mathbf{M}$ & $\boldsymbol{v}(\mathbf{N}-\mathbf{H})$ & $\boldsymbol{v}(\mathbf{C}=\mathbf{S})$ \\
\hline $\mathbf{1 a}$ & $\mathrm{H}$ & - & $3154 / 3243 / 3375$ & 826 \\
$\mathbf{2 a}$ & $\mathrm{Me}$ & - & $3193 / 3366$ & 836 \\
$\mathbf{3 a}$ & $\mathrm{Et}$ & - & $3201 / 3299$ & 829 \\
$\mathbf{1 b}$ & $\mathrm{H}$ & $\mathrm{Pd}$ & $3159 / 3292$ & - \\
$\mathbf{2 b}$ & $\mathrm{Me}$ & $\mathrm{Pd}$ & 3353 & - \\
$\mathbf{3 b}$ & $\mathrm{Et}$ & $\mathrm{Pd}$ & 3341 & - \\
$\mathbf{4 b}$ & $\mathrm{H}$ & $\mathrm{Pt}$ & $3215 / 3320$ & - \\
$\mathbf{5 b}$ & $\mathrm{Me}$ & $\mathrm{Pt}$ & 3286 & - \\
$\mathbf{6 b}$ & $\mathrm{Et}$ & $\mathrm{Pt}$ & 3303 & - \\
\hline
\end{tabular}

\section{2. ${ }^{1} \mathrm{H}$ NMR Spectroscopy}

The comparison of the spectra (in Figure 1) for the thiosemicarbazone ligands and cyclometallated compounds shows the disappearance of the ortho aromatic proton resonance and the hydrazinic proton resonance in agreement with cyclometallation. 
Moreover, aromatic signals change their multiplicity upon formation of the $\mathrm{Pd}-\mathrm{C}$ bond.

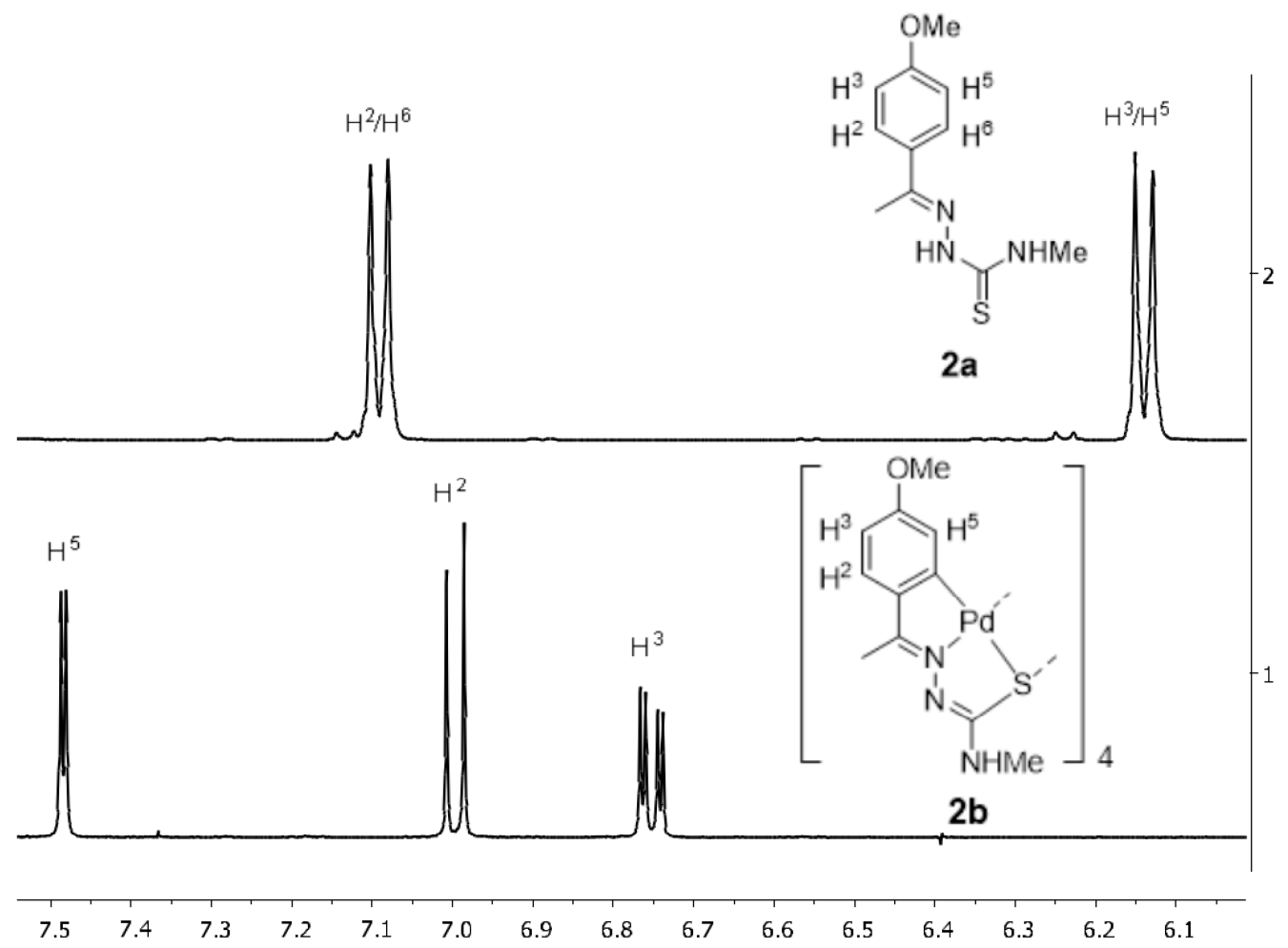

Figure 1. ${ }^{1} \mathrm{H}$ NMR stacked spectrum (400 MHz, DMSO-d 6 ) for compounds $\mathbf{2 a}$ and $\mathbf{2 b}$.

After reaction with dppm, the spectra did not show very significant changes, as shown in Figure 2. The only remarkable change is the high field shift of the $\mathrm{H}^{5}$ proton signal, caused by the phenyl rings of the diphosphine, which produces strong shielding in that position.

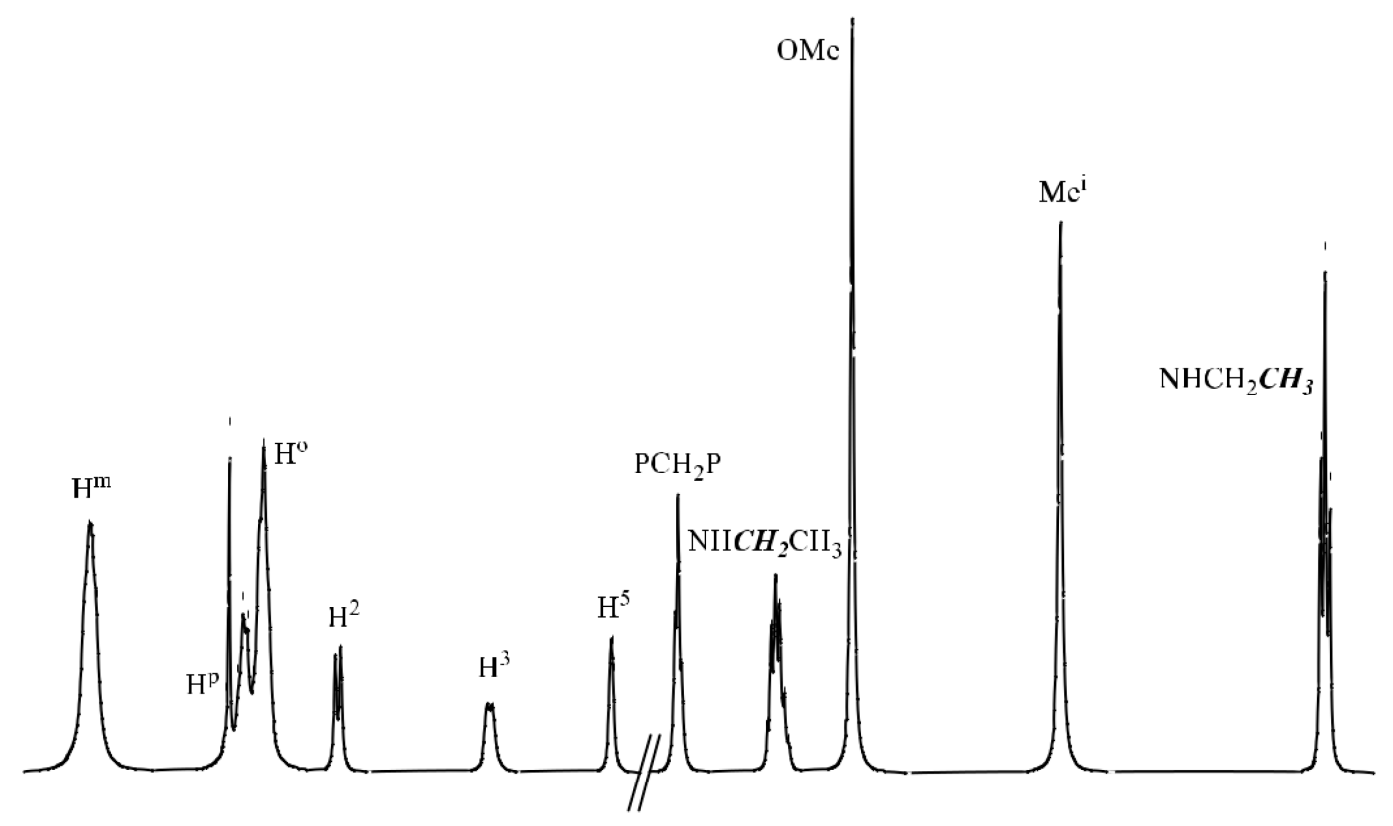

$\begin{array}{llllllllllllllllllllllllllllll}8.0 & 7.8 & 7.6 & 7.4 & 7.2 & 7.0 & 6.8 & 6.6 & 6.4 & 6.2 & 6.0 & 5.8 & 5.6 & 3.8 & 3.6 & 3.4 & 3.2 & 3.0 & 2.8 & 2.6 & 2.4 & 2.2 & 2.0 & 1.8 & 1.6 & 1.4 & 1.2\end{array}$

Figure 2. ${ }^{1} \mathrm{H}$ NMR spectrum of compound $3 \mathrm{c}$ in $\mathrm{CDCl}_{3}$. 


\section{3. ${ }^{31} P-\left\{{ }^{1} H\right\} N M R$ spectroscopy}

The ${ }^{31} \mathrm{P}$ NMR spectrum gives information about the coordinative behavior of the phosphine ligand.

In this case, the spectra show two doublets, one for each of the two inequivalent ${ }^{31} \mathrm{P}$ nuclei.

Satellites due to ${ }^{195} \mathrm{Pt}-{ }^{31} \mathrm{P}$ coupling were observed for $4 \mathrm{c}-6 \mathrm{c}$ (see Figure 3).

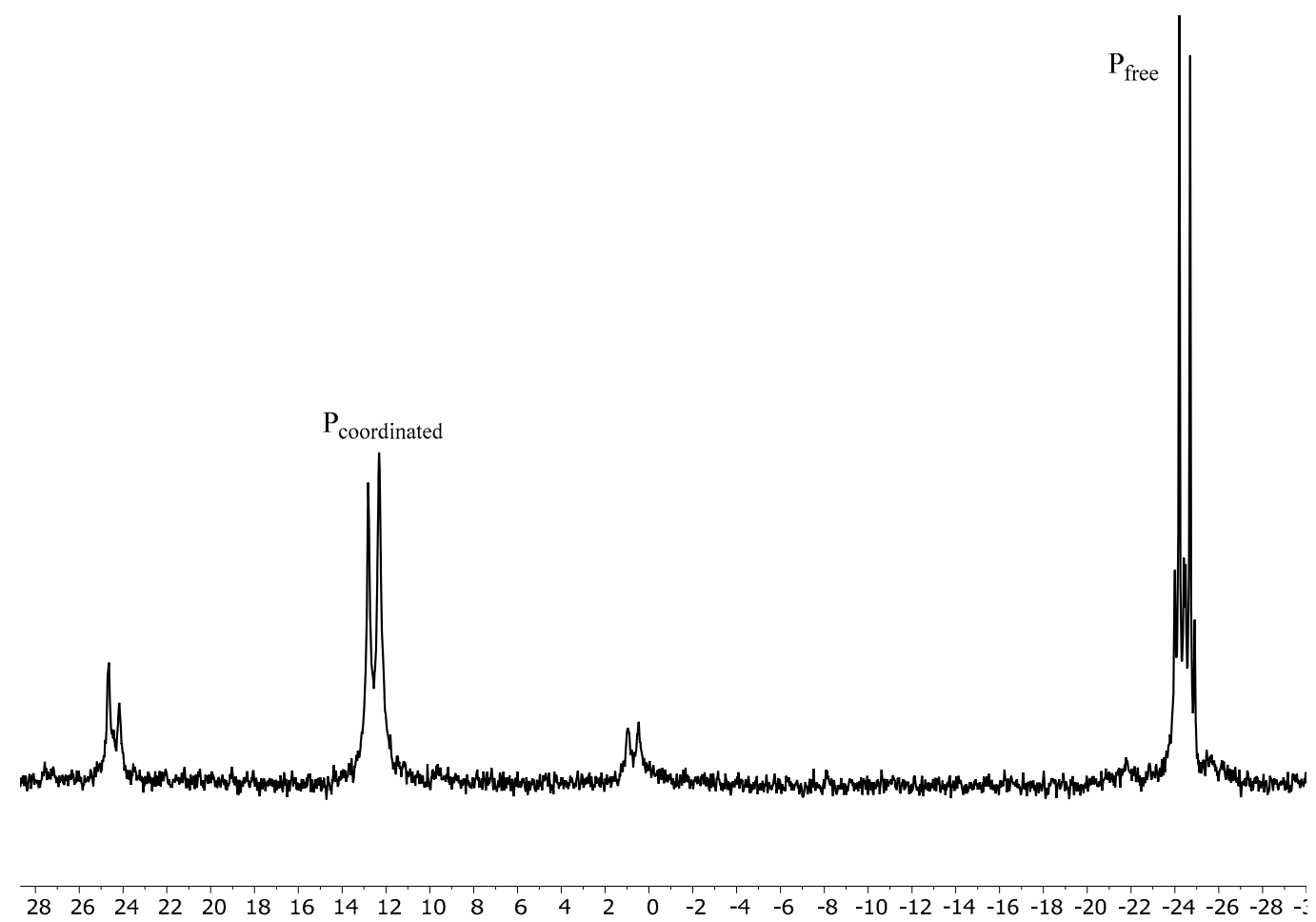

Figure 3. ${ }^{31} \mathrm{P}-\{1 \mathrm{H}\}$ NMR of compound $5 \mathrm{c}$ in acetone- $\mathrm{d} 6$.

\subsection{Single Crystal X-ray Diffraction}

Single crystals for compound 1c were obtained by slow evaporation of an acetone solution.

Compound 1c crystallizes in the monoclinic system, C2/c space group. The resolution of the molecular structure confirms the spectroscopic data. The molecular structure of $1 \mathrm{c}$ is shown in Figure 4 and selected bond distances $(\AA)$ and angles $\left(^{\circ}\right)$ are shown in Table 5 .

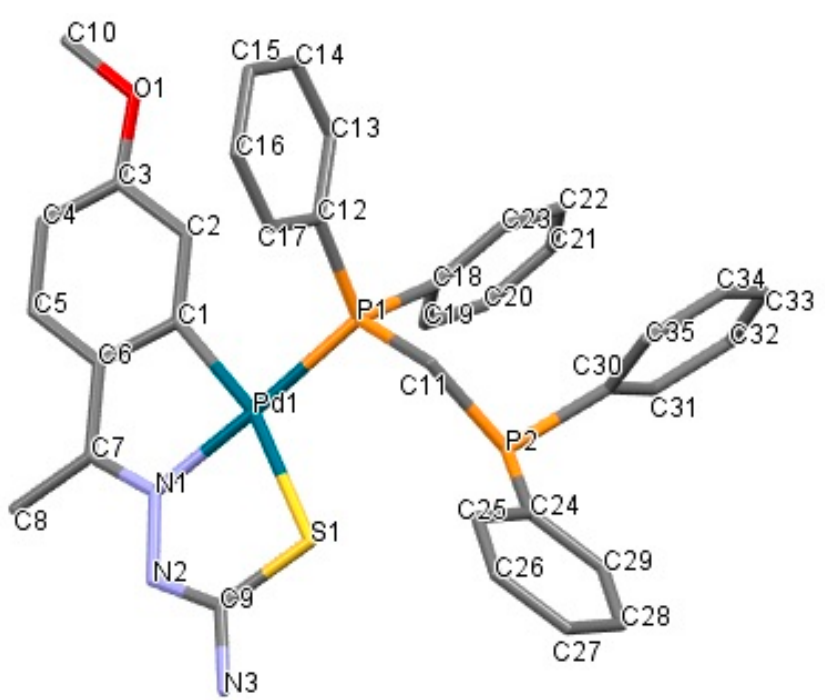

(a)

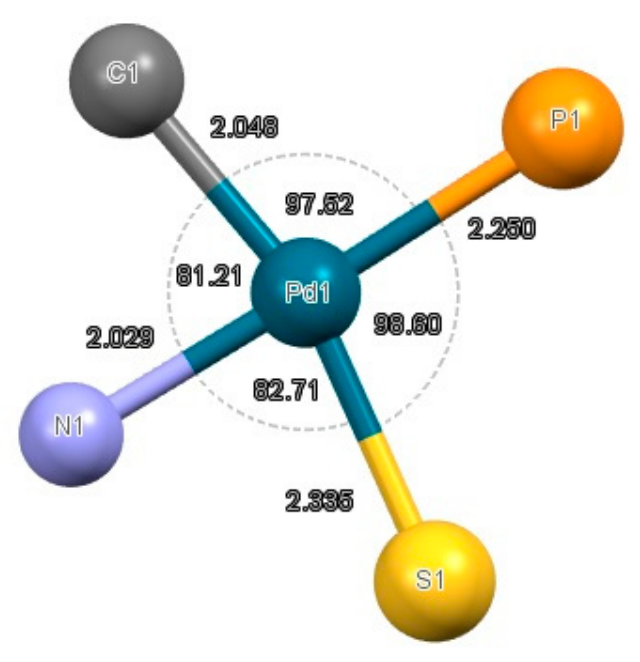

(b) 


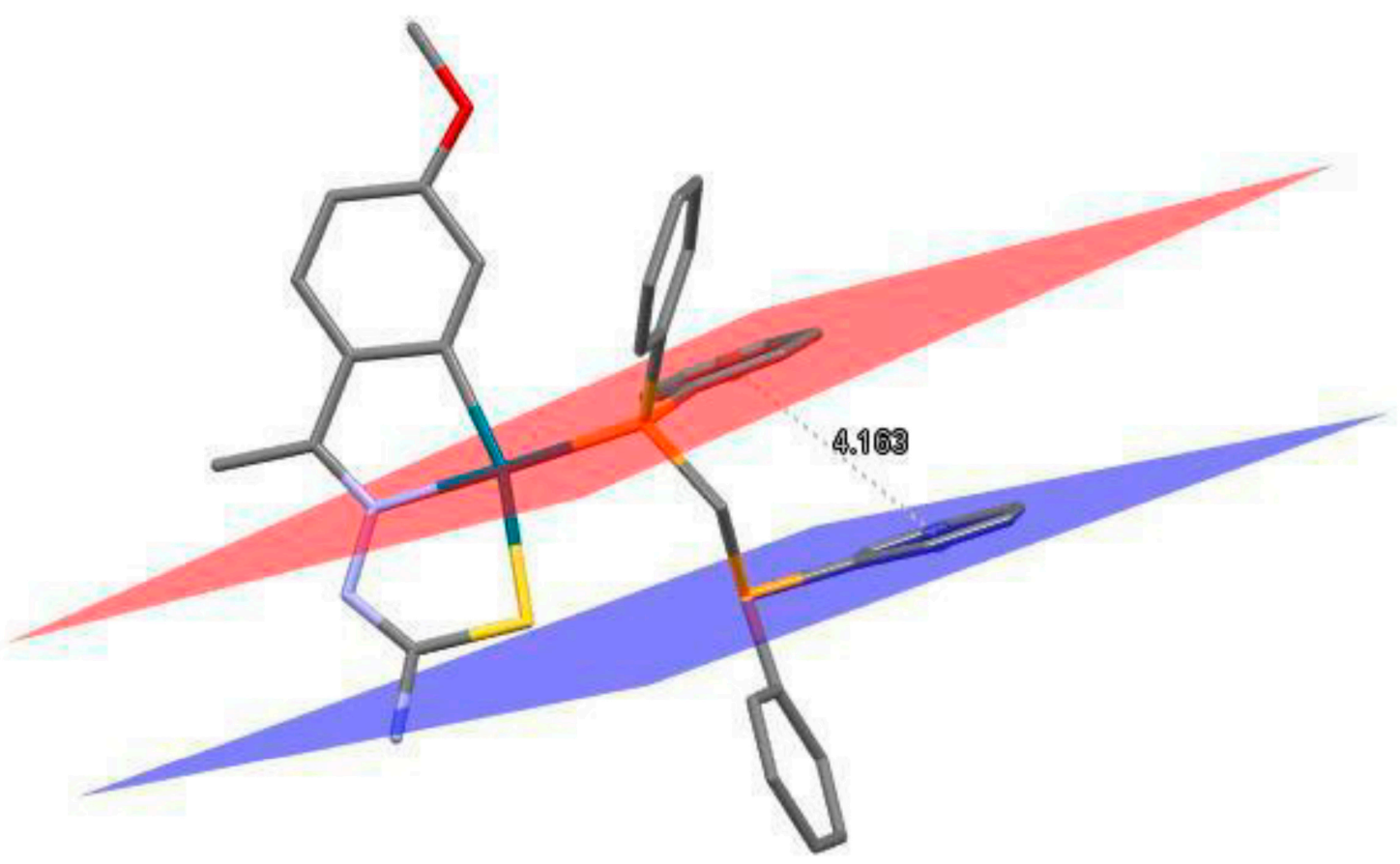

(c)

Figure 4. (a) Molecular structure of compound 1b. Hydrogen atoms have been omitted for clarity. (b) Bond distances $(\AA)$ and angles $\left({ }^{\circ}\right)$ around the palladium center. (c) Intramolecular $\pi-\pi$ stacking interaction in 1c.

Complex 1c (shown in Table 5) presents a mononuclear structure, with slightly distorted squareplanar geometry around the palladium center, surrounded by the ortho carbon atom of the phenyl ring (C1), the iminic nitrogen (N1), the sulfur (S1) and one phosphorus atom (P1). Selected bonds distances and angles are presented in Table 5. The sum of angles about palladium atom is

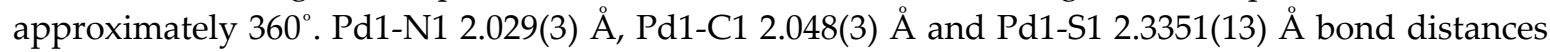
are within the expected range, and they are in agreement with similar structures previously presented by us [12-14].

Table 5. Selected bonds $(\AA)$ and angles $\left(^{\circ}\right)$ for compound 1c.

\begin{tabular}{cccc}
\hline $\mathrm{Pd}(1)-\mathrm{N}(1)$ & $2.029(3)$ & $\mathrm{S}(1)-\mathrm{C}(9)$ & $1.762(3)$ \\
\hline $\operatorname{Pd}(1)-\mathrm{C}(1)$ & $2.048(3)$ & $\mathrm{N}(1)-\mathrm{C}(7)$ & $1.305(4)$ \\
$\operatorname{Pd}(1)-\mathrm{P}(1)$ & $2.2504(8)$ & $\mathrm{N}(1)-\mathrm{N}(2)$ & $1.379(4)$ \\
$\operatorname{Pd}(1)-\mathrm{S}(1)$ & $2.3351(13)$ & $\mathrm{N}(2)-\mathrm{C}(9)$ & $1.305(4)$ \\
$\mathrm{N}(1)-\operatorname{Pd}(1)-\mathrm{C}(1)$ & $81.22(12)$ & $\mathrm{N}(1)-\mathrm{Pd}(1)-\mathrm{S}(1)$ & $82.70(8)$ \\
$\mathrm{N}(1)-\mathrm{Pd}(1)-\mathrm{P}(1)$ & $177.18(8)$ & $\mathrm{C}(1)-\mathrm{Pd}(1)-\mathrm{S}(1)$ & $163.87(10)$ \\
$\mathrm{C}(1)-\mathrm{Pd}(1)-\mathrm{P}(1)$ & $97.52(10)$ & $\mathrm{P}(1)-\mathrm{Pd}(1)-\mathrm{S}(1)$ & $98.60(4)$ \\
\hline
\end{tabular}

Intramolecular $\pi-\pi$ stacking interactions were observed between two phenyl rings, one from each phosphorus atom (see Figure 4c).

The distance between the two centroids is $4.163 \AA$, and the angle between the ring planes is $3.43^{\circ}$.

In addition, intermolecular hydrogen bond interactions were observed between the hydrazinic nitrogen and the thioamidic nitrogen. The hydrogen bond distances were $2.127 \AA$, as shown in Figure 5 . 


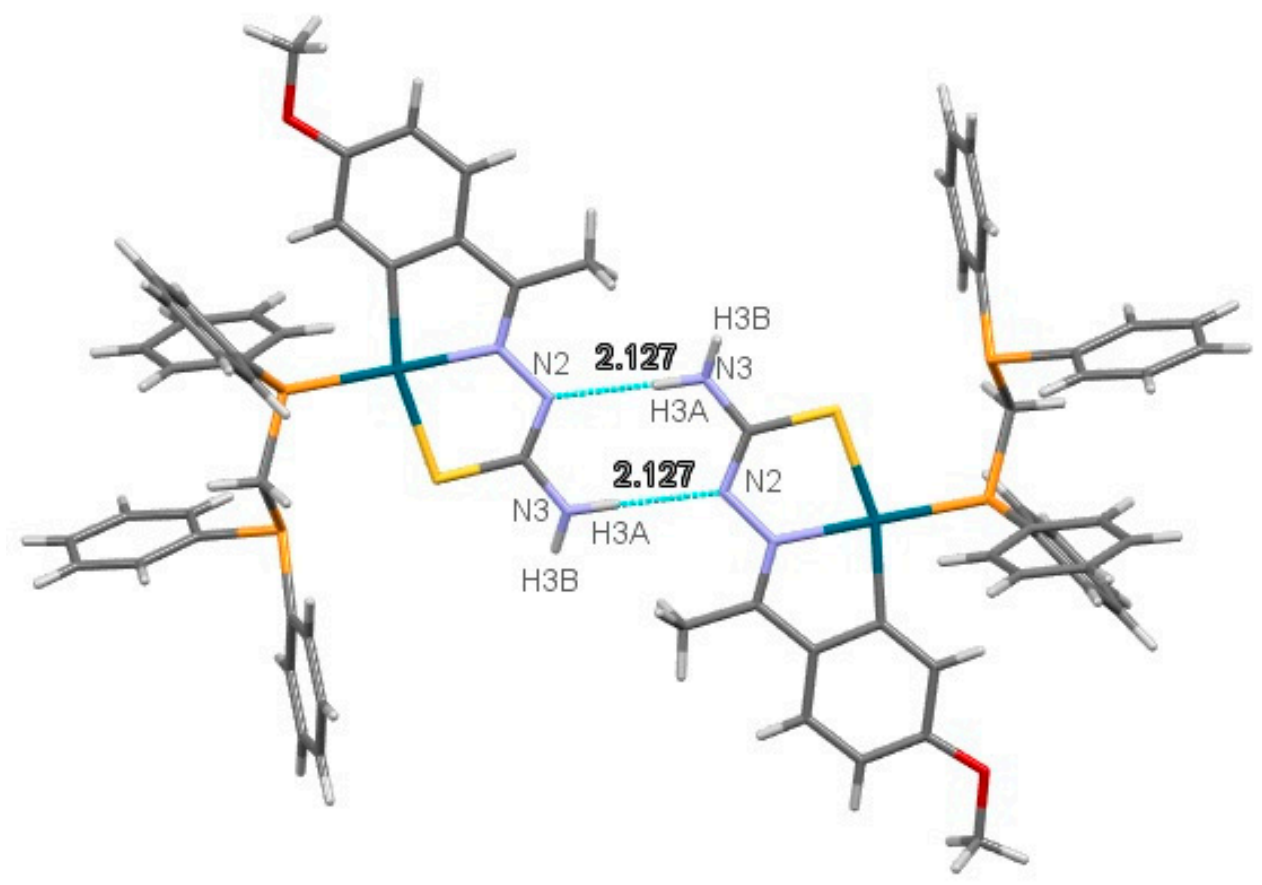

Figure 5. Intermolecular hydrogen bonding interaction in 1c.

\section{Conclusions}

- Coordination to the metal center occurs in the thiol form of the thiosemicarbazone ligand, as shown by IR spectroscopy.

- ${ }^{1} \mathrm{H}$ NMR spectroscopy confirms cyclometallation, with the thiosemicarbazone ligand as tridentate $[C, N, S]$.

- The cyclometallated compounds show a tetranuclear structure, with two types of bonds between palladium and sulfur: Pd-Schelate and Pd-Sbridging.

- Reaction with dppm generates mononuclear compounds with one free phosphorus atom.

- Single crystal X-ray diffraction study of compound 1c shows the proposed structure, with the palladated thiosemicarbazone ligand and dppm as a monodentate ligand.

Funding: Francisco Reigosa wants to thank the Spanish Government (AEI) for their financial support through an FPU grant (number 13/05014). The authors thank funding from Xunta de Galicia (Galicia, Spain) under the Grupos de Referencia program (GRC 2019/014).

Conflicts of Interest: The authors declare no conflict of interest.

\section{References}

1. Ramírez-Rave, S.; Morales-Morales, D.; Grévy, J.-M. Microwave assisted Suzuki-Miyaura and MizorokiHeck cross-couplings catalyzed by non-symmetric $\operatorname{Pd}(\mathrm{II})$ CNS pincers supported by iminophosphorane ligands. Inorg. Chim. Acta 2017, 462, 249-255.

2. Dharani, S.; Kalaiarasi, G.; Sindhuja, D.; Lynch, V.M.; Shankar, R.; Karvembu, R.; Prabhakaran, R. Tetranuclear Palladacycles of 3-Acetyl-7-methoxy-2H-chromen-2-one Derived Schiff Bases: Efficient Catalysts for Suzuki-Miyaura Coupling in an Aqueous Medium. Inorg. Chem. 2019, 58, 8045-8055.

3. López-Mosquera, C.; Grabulosa, A.; Rocamora, M.; Font-Bardia, M.; Muller, G. Cyclopalladated Compounds with Polyhalogenated Benzylphosphanes for the Mizoroki-Heck Reaction. Eur. J. Inorg. Chem. 2020, 2020, 2470-2484.

4. Zhang, D.; Yu, J. Fine Tuning of Chiral Bis(N-heterocyclic carbene) Palladium Catalysts for Asymmetric Suzuki-Miyaura Cross-Coupling Reactions: Exploring the Ligand Modification. Organometallics 2020, 39, 1269-1280. 
5. Avila-Sorrosa, A.; Estudiante-Negrete, F.; Hernández-Ortega, S.; Toscano, R.A.; Morales-Morales, D. Buchwald-Hartwig C-N cross coupling reactions catalyzed by a pseudo-pincer $\mathrm{Pd}(\mathrm{II})$ compound. Inorg. Chim. Acta 2010, 363, 1262-1268.

6. Kostas, I.D.; Steele, B.R. Thiosemicarbazone Complexes of Transition Metals as Catalysts for CrossCoupling Reactions. Catalysts 2020, 10, 1107.

7. Fong, T.T.-H.; Lok, C.-N.; Chung, C.Y.-S.; Fung, Y.-M.E.; Chow, P.-K.; Wan, P.-K.; Che, C.-M., Cyclometalated Palladium(II) N-Heterocyclic Carbene Complexes: Anticancer Agents for Potent In Vitro Cytotoxicity and In Vivo Tumor Growth Suppression. Angew. Chem. Int. Ed. 2016, 55, 11935-11939.

8. Tabrizi, L.; Zouchoune, B.; Zaiter, A. Experimental and theoretical investigation of cyclometallated platinum (ii) complex containing adamantanemethylcyanamide and 1,4-naphthoquinone derivative as ligands: Synthesis, characterization, interacting with guanine and cytotoxic activity. RSC Adv. 2019, 9, 287300.

9. Özerkan, D.; Ertik, O.; Kaya, B.; Kuruca, S.E.; Yanardag, R.; Ülküseven, B. Novel palladium (II) complexes with tetradentate thiosemicarbazones. Synthesis, characterization, in vitro cytotoxicity and xanthine oxidase inhibition. Invest. New Drug 2019, 37, 1187-1197.

10. Yousef, T.A.; Abu El-Reash, G.M. Synthesis, and biological evaluation of complexes based on thiosemicarbazone ligand. J. Mol. Struct. 2020, 1201, 127180.

11. Pike, S.; Lord, R.; Kergreis, A. Influence of Ligand and Nuclearity on the Cytotoxicity of Cyclometallated $\mathrm{C}^{\wedge} \mathrm{N}^{\wedge} \mathrm{C}$ Platinum (II) Complexes. Chem. Eur. J. 2020, 26, 14938.

12. Lucio-Martínez, F.; Adrio, L.A.; Polo-Ces, P.; Ortigueira, J.M.; Fernández, J.J.; Adams, H.; Pereira, M.T.; Vila, J.M. Palladacycle catalysis: An innovation to the Suzuki-Miyaura cross-coupling reaction. Dalton Trans. 2016, 45, 17598-17601.

13. Martínez, J.; Cabaleiro-Lago, E.M.; Ortigueira, J.M.; Pereira, M.T.; Frieiro, P.; Lucio, F.; Vila, J.M. Synthesis and reactivity of thiosemicarbazone palladacycles. Crystal structure analysis and theoretical calculations. Inorg. Chim. Acta 2016, 449, 20-30.

14. Lucio-Martínez, F.; Bermúdez, B.; Ortigueira, J.M.; Adams, H.; Fernández, A.; Pereira, M.T.; Vila, J.M. A Highly Effective Strategy for Encapsulating Potassium Cations in Small Crown Ether Rings on a Dinuclear Palladium Complex. Chem. Eur. J. 2017, 23, 6255-6258.

Publisher's Note: MDPI stays neutral with regard to jurisdictional claims in published maps and institutional affiliations.

(C) 2021 by the authors. Licensee MDPI, Basel, Switzerland. This article is an open access article distributed under the terms and conditions of the Creative Commons Attribution (CC BY) license (http://creativecommons.org/licenses/by/4.0/). 